\title{
Characterizing Perception of Ecological Risk
}

Timothy McDaniels,,$^{1,2}$ Lawrence J. Axelrod, ${ }^{1}$ and Paul Slovic ${ }^{3}$

1 University of British Columbia, Westwater Research Centre and School of Community \& Regional Planning, 433-6333 Memorial Rd.; Vancouver, British Columbia V6T 1Z2, Canada.

2 To whom correspondence should be addressed.

3 Decision Research, 1201 Oak St., Eugene, Oregon 97401-3575. 


\begin{abstract}
Relatively little attention has been paid to the role of human perception and judgment in ecological risk management. This paper attempts to characterize perceived ecological risk, using the psychometric paradigm developed in the domain of human health risk perception. The research began by eliciting a set of scale characteristics and risk items (e.g., technologies, actions, events, beliefs) from focus group participants. Participants in the main study were 68 university students who completed a survey instrument that elicited ratings for each of 65 items on 30 characteristic scales and one scale regarding general risk to natural environments. The results are presented in terms of mean responses over individuals for each scale and item combination. Factor analyses show that five factors characterize the judgment data. These have been termed impact on species, human benefits, impact on humans, avoidability, and knowledge of impacts. The factor results correspond with initial expectations and provide a plausible characterization of judgments regarding ecological risk. Some comparisons of mean responses for selected individual items are also presented.
\end{abstract}

KEY WORDS: Risk perception, ecological risk analysis 


\section{INTRODUCTION}

Managing risk to human health and safety has, over the last two decades, become a dominant theme in government policy, public debate, media attention, and academic research. A striking aspect of this growth is the increasing attention paid to human perception and judgment in debates that were initially characterized as based completely in science and technology. One line of research involving human judgment had its origins in experimental work that adapted psychometric scaling methods to characterize people's perceptions of the relative riskiness of technologies. ${ }^{(1,2)}$ Recent research on perceived health risk has provided insight into key social aspects of health risk management, including how best to communicate information about health risks, ${ }^{(3)}$ the social amplification of risk impacts, ${ }^{(4.5)}$ risk-induced stigmatization of products, places, and technologies, ${ }^{(6)}$ and the determinants of value judgments underlying health risk tradeoffs. ${ }^{(7)}$

In recent years, ecological risks (threats to the health and productivity of species and ecosystems) have also arisen as a topic of great public concern, in parallel with heightened attention to resource sustainability and concern over environmental degradation. Examples of ecological risks range from specific threats to localized ecosystems from development or pollution to threats to global ecosystems from climate change. While the risk management community has recognized the increasing need for serious research on ecological risk management, ${ }^{(8-10)}$ much of the work thus far has been undertaken from the perspective of the physical and biological sciences. Relatively little effort has been devoted to social science questions regarding human perception, mental characterization, value assessment, or decisionmaking structures regarding ecological risks. 
This article begins to address that gap. It presents a framework for characterizing ecological risk perception, building on the psychometric risk perception paradigm that emerged from the study of risks to human health. ${ }^{(1,2)}$ In simple terms, our primary objective is to clarify what people mean when they say something is risky to the environment. We attempt to identify the characteristics that lead individuals to perceive one activity as a high ecological risk, and another activity as less so.

The psychometric paradigm is an approach for identifying the characteristics influencing people's perceptions of risk. The approach assumes that risk is inherently multidimensional, with many characteristics other than the probability of harm affecting individual judgments. Applying the method to human health risk perception includes:

1. Developing a list of hazard items or risky events, technologies, and practices that span a broad domain of potential hazards.

2. Developing a number of psychometric scales that reflect characteristics of risks that are important in shaping human perception of, and response to, different hazards.

3. Asking people to evaluate the list of items on each of the scales.

4. Using multivariate statistical methods (such as factor analysis), to identify and interpret a set of underlying factors that capture the variation in the individual and group responses. ${ }^{(2)}$

The present study follows these basic steps. However, in this study we assume that there are substantial differences between judgments of perceived health risk and perceived ecological risk, with the most fundamental difference being the greater complexity of ecological risk judgments ${ }^{(8)}$ One source of complexity is the wider range of possible end states of interest. Ecological health is less well defined than human health and will have a much wider array of 
meanings. ${ }^{(8)}$ For example, does a naturally occurring hazard (e.g., a flood or an earthquake) or a hazard that threatens humans pose ecological risk? A second source of complexity is the potentially greater influence of personal characteristics of people (e.g., worldviews, value orientations, and prior experience with nature and potential hazards). These variables could be more influential because of the greater diversity of opinion regarding what ecological risk means in systems where natural forces themselves create massive changes in species and their habitats. Still another source of complexity is the great variation in the physical scale of ecological systems, which can range from a few square meters of plants to the risk of global ecological change. One final and subtle source of complexity may be the concern for entire ecological systems and species, rather than effects on individuals.

Given this complexity, we assumed that many new sets of scales and items would be required to characterize respondents' judgments about ecological risks. We developed these scales and items through a series of focus groups, as described in the next section. In sum, even though we followed the basic steps of the human health risk perception approach, the survey instrument in this study and the concepts it examines were developed specifically to address ecological risks.

We began the study with a number of expectations, drawn from various sources, regarding the kinds of factors that would eventually characterize ecological risk perception. We expected that possible influences could include the potential for loss of species and ecosystems; the potential for more conventional environmental impacts (e.g., water pollution) that directly affect human uses of natural resources; the potential scope and destructiveness of impacts; the potential influence of dread and knowledge as indicated in the human health-risk perception 
literature; and the perceived benefits to humans. ${ }^{(14,15)}$ In sum, we expected that a substantial number of dimensions could be important in characterizing perceived ecological risk.

\section{METHOD}

\subsection{Participants}

Participants in the study were 40 women and 28 men who were recruited from the student population at the University of British Columbia. They averaged 23 years in age, with a range of 18 to 39 . The sample included students from most of the faculties and academic disciplines at the university. Although this sample is small, and its members are clearly not representative of the general public (being younger and better educated on average), several previous studies have used such samples to explore risk perception issues. ${ }^{(1)}$ The sample was recruited through advertisements seeking individuals interested in a few hours of paid work filling out a survey. Participants took between 2 and 3 hours to complete the survey instrument and were paid either $\$ 20.00$ or $\$ 25.00$, depending on the time required.

\subsection{Item and Scale Development}

As a first step in developing the survey instrument, four focus groups were held to help identify (a) items that may be perceived as risks to the health and productivity of natural environments, and (b) scales reflecting characteristics of these items that may influence the judgment of risk. Two of the groups consisted of participants from a range of backgrounds including environmental managers, environmental activists, service workers, union members, and university students. A third group consisted of academic specialists concerned with the biological and societal dimensions of natural environments. Participants in the fourth group were members of a high school English class. An open discussion format was employed in each 
focus group, in which participants were prompted to discuss freely the two issues noted above. These discussions were lively and expansive, arousing enthusiasm and emotion in the participants. Information gathered from these focus groups was structured using content analytic procedures, ${ }^{1}$ and comprehensive lists of risky items and characteristics were generated. These lists were then reviewed by the researchers to eliminate any redundancies and to ensure item and scale clarity.

\subsubsection{Items}

The final list included 65 items that were perceived as posing some level of ecological risk. The set of items derived from the focus groups was extremely broad, and included a vast range of human endeavors and natural phenomena. Four general groupings in these items could be identified, although some overlap among classifications is unavoidable. One grouping contained natural disasters (i.e., earthquakes, volcanos, drought, floods, and meteors colliding with Earth); a second involved technologies and their applications (e.g., fertilizers, pesticides, mass production farming practices, oil transportation, incineration). A third grouping included human practices that were seen as potentially having some negative environmental impact (e.g., poaching, disposal of different kinds of waste products, driving automobiles, cigarette smoking, beef production, tourism and travel, scuba diving). The fourth grouping included human beliefs and political/social systems (e.g., capitalism, consumer-oriented society, disconnection of modern life from natural environments, human dominion over nature). Items in this latter grouping generated substantial discussion (and emotion) during the focus groups. Although the link between some items and ecological risk may not be obvious (e.g., television), their inclusion in the final list was consistent with the goals of representing the diverse perspectives raised in the focus groups. 
The list also included items that are indirect sources of risk (e.g., air conditioning, aerosol cans), direct sources of risk (e.g., emission of ozone depleting gases), and consequences of risks (e.g., ozone depletion). Thus, several of the items are directly related, with some being causes of others. We adopted this approach to clarify differences in people's judgments about these linked items. In addition, although all 65 items could be perceived as posing some level of risk, items were included that were reasonably expected to be rated as not very. risky (e.g., scuba diving, outdoor recreation) as well as items that likely posed substantial risk (e.g., global warming, acid rain, population growth, loss of animal species). The entire set of items is presented later, in Table III, with the results.

\subsubsection{Scales}

In contrast to previous research in risk perception, where the relevant characteristics of risks have been largely based on theory and literature reviews, ${ }^{(1)}$ we developed judgment scales reflecting risk characteristics based on information obtained from the focus groups. From this approach, 31 scales (including one "general risk" scale) were developed to characterize the ecologically risky items. A number of the scales paralleled those found to have explanatory value in studies of human health risk-perception (e.g., ref. no. 1). Examples of these include observability of potential consequences associated with the item, knowledge of the risks, the severity of the consequences, and the controllability of the potential impacts. The dread scale, which plays such a prominent role in health risk perception research, has in this study an analog worded in terms of negative emotion. That is because focus group participants sometimes mentioned sadness, anger, disgust, or frustration in discussion of certain ecological risks, but the notion of personal dread (fear) was never mentioned or apparent. ${ }^{2}$ Several scales were identified in the focus groups that are specific to ecological risk (e.g., ability of natural environments to 
adapt, species loss). In addition, two other types of scales were derived. First, in keeping with recent research, ${ }^{(14,15)}$ some focus group members suggested that the benefits associated with an item may influence the perceived risk associated with that item. Thus, three scales were included (i.e., benefits to society, benefits to persons, and overall goodness). Second, ethical dimensions were mentioned in each of the focus groups. In response, several scales were developed that addressed these considerations (i.e., ethicality, infringement on the rights of nonhuman species, extent of suffering to humans and nonhuman species). Finally, the general risk posed by each item to the "health and productivity of natural environments" was assessed. The complete set of rating scales is shown in Table I along with the response categories as provided to the participants.

Insert Table I about here

\subsection{The Questionnaire}

The questionnaire began with an introduction that provided a definition of ecological risk as "uncertain potential for harm to the health and productivity of natural environments." Participants were instructed to rate each item on judgment scales that ranged from 1 to 7 , with 4 being the midpoint. They rated each of the 65 items on the set of 31 scales, each of which reflected one characteristic of the items. Participants rated the entire set of 65 items on one characteristic scale before going on the next scale. A final section of the questionnaire collected demographic information (i.e., age, sex, major area of study) and attitudinal information. 


\section{RESULTS}

\subsection{Mean Ratings}

An initial step in analyzing the data was to recode the 1 to 7 scale into a scale with endpoints of -3 and 3 , and a midpoint of 0 . This recoding procedure was done to highlight the relationship between responses and the scale midpoint. A second step was to create a data matrix of mean responses over all individuals, for each combination of scale and item. Table II presents the means and standard deviations for all the scales across all respondents and across the 65 items ordered in terms of the mean rating. Several scales had means well dispersed from the scale midpoint. The most extreme mean was for the certainty of impacts scale $(M=1.54)$, followed by the goodness scale $(M=-1.33)$, the infringement on the rights on nonhuman species scale $(M=$ 1.31), and the animal/plant suffering scale $(M=1.31)$. On average, respondents perceived the items to be bad, and, with a high degree of certainty, to have substantial impact on nonhuman species.

Insert Table II about here

The mean for the animal/plant suffering scale $(M=1.31)$ was higher than the mean for the human suffering scale $(M=.59), t=7.20, p<.01$. This difference not only suggests that greater suffering is perceived to occur in nature as a result of the rated items, but that respondents were differentiating risks to nature from risks to humans. Another notable difference can be observed by comparing the social benefit and personal benefit scales, where on average respondents indicated they benefitted less personally from the group of items $(M=-1.29)$ than did society as a whole $(M=-1.00), t=6.04, p<.01$. 
In terms of the variability of responses across items, the highest standard deviations were found for the two benefit scales (societal $=1.31$, personal $=1.32$ ), followed closely by the regulatability scale. The emotionality scale also had a high standard deviation (1.23), with some items eliciting very negative emotional responses and other items being perceived as emotionally benign. The emotionality scale also had the widest range of mean responses with a low score of -2.43 (outdoor recreation) as compared to a high score of 2.93 (nuclear war).

Table III presents the 65 items ordered in terms of their mean rating of overall risk to natural environments. These means were also very diverse, ranging from a low of -1.85 to a high of 2.69. On average, though, these items were perceived to pose a moderate level of risk to natural environments $(M=1.13)$ and somewhat less risk to human health $(M=.68)$. In terms of specific items, outdoor recreation $(M=-1.85)$, scuba diving $(M=-1.78)$, fireplaces $(M=-1.42)$, travel and tourism $(M=-.86)$, golf courses $(M=-.72)$, television $(M=-.56)$ and collecting wilderness souvenirs $(M=-.53)$ were rated as posing the least risk to natural environments. No otherr item had a negative rating. In contrast, nuclear war $(M=2.69)$, loss of animal species $(M=2.53)$, ozone depletion $(M=2.51)$ and loss of plant species $(M=2.51)$ were rated as posing the highest risks to natural environments.

\section{Insert Table III about here}

\subsection{Intercorrelations Among Scales}

Table IV presents the intercorrelations among mean ratings for all 31 scales. A review of the matrix shows high associations between some scales (e.g., social benefit and personal benefit, $r=$ .96) and no association between others (e.g., social benefit and availability of alternatives, $r=$ .03). More than half of the characteristics had correlations of 80 or higher with general riskiness, 
and five scales (i.e., certainty of impacts, destructiveness, emotionality, goodness, and acceptability) had correlations of .90 or higher.

\section{Insert Table IV about here}

The bottom row of Table IV shows that several scales had relatively low correlations with general risk to nature including avoidability $(r=.13)$, controllability $(r=-.22)$, ability to regulate $(r=.11)$ and availability of alternatives $(r=.21)$. Interestingly, these four scales all reflect aspects of society's ability to manage the risk. The findings of such low associations with risk to nature is a contrast with studies of perceived risk to humans, where controllability over the item has been found to be highly correlated with overall riskiness (e.g., ref. no. 16).

\subsection{Factor Analysis of Scale Intercorrelations}

The matrix in Table IV indicated a substantial degree of correlation for many pairs of scales. This suggests that there may be some underlying dimensions that could more compactly explain the overall variance in the data. Factor analysis has been employed in many human health risk perception studies to identify such dimensions. ${ }^{(2)}$ Thus, we conducted a factor analysis of the correlation matrix in Table IV.

Table $\mathrm{V}$ presents the summary of a principle components factor analysis with varimax rotation performed on the interrelation among the mean responses for the 30 risk characteristics. Five orthogonal factors with eigenvalues greater than 1.0 emerged from the analysis. The first factor accounted for slightly under $56 \%$ of the variance in the data. Factor 2 accounted for $18 \%$, followed by $9 \%, 5 \%$, and $3 \%$ for factors 3,4 , and 5 , respectively. Even though the last three factors accounted for substantially smaller amounts of variance than the first two, they were 
retained because of their conceptual relevance and to maintain clarity and comprehensiveness in the factor structure.

\section{Insert Table $\mathrm{V}$ about here}

Loss of animal and plant species, infringement on rights of species and rate of animal/plant suffering were the three highest loaded scales on Factor 1 in Table V. Thus, we label this factor impact on species. The highest loaded scales on Factor 2 in Table V were benefits for society resulting from the items and benefits for individuals. We label this factor human benefits. The third factor included a number of scales related to the extent of impacts, particularly to humans, including number of people affected, risks to human health, and scope of impacts. This factor could be viewed as impact on humans, although from an ecological perspective it could be viewed as the scope of impacts. We adopt impact on humans here because of the parallels with the first two factor labels. The fourth factor had the tightest grouping of scales and included the four characteristics related to risk management and control (i.e., controllability, avoidability of impacts, availability of alternatives, ability to regulate). We label this factor avoidability, though controllability might also be an appropriate label. The fifth and weakest factor, both in terms of variance explained and magnitude of factor loading scores, represented the ability to observe, predict, recognize, and understand the impacts of the items. We refer to this factor as knowledge of impacts.

Factor scores for each item were computed by weighting the ratings on each risk scale proportionally to the scale's importance in determining each factor and then summing across all scales, resulting in five factor scores for each item. Table VI shows the 20 extreme items (10 highest and 10 lowest) on each factor. As would be expected, the loss of wetlands, plant species, 
animal species, and habitats were perceived as the most extreme items in terms of Factor 1 , impact on species. In contrast, cigarettes, scuba diving, and fireplaces had the lowest impact on species. Interestingly, three natural hazards (i.e., earthquakes, floods, and drought) also were ranked low on impacts on species. Earthquakes and floods also appeared as two of the items that ranked lowest on Factor 2, human benefits. Cigarette smoking was rated as the least beneficial of the 65 items, whereas outdoor recreation, housing, travel and automobiles were perceived as the most beneficial to humans. Turning to Factor 3, impact on humans, automobiles were ranked as having the highest impact, followed closely by ozone depletion, air pollution, and CFC emissions. Somewhat surprising is the absence of cigarette smoking from the items ranked high in impact on humans. Collecting wilderness souvenirs, scuba diving, golf courses, poaching, and hunting were perceived as lowest in terms of impact on humans. As expected, the natural hazards were perceived as the least avoidable items (Factor 4). There was also a perception that three dominant forces in North American life (economic growth, capitalism, and reliance on technology) were not perceived as avoidable. In addition, population growth was rated as not avoidable. Smoking cigarettes, use of aerosol cans, golf courses, and clearcutting of forests were rated as the most avoidable items. Untreated sewage was also seen as quite avoidable. Several items were perceived as having ecological impacts that are relatively unknown (Factor 5). These include television, biotechnology, meteors, and scuba diving. Knowledge regarding global warming was also considered as low. In contrast, respondents seemed to think that a good deal is known about the ecological impacts of earthquakes, clearcutting of forests, deforestation, and automobiles.

Insert Table VI about here 


\subsection{Risk Perception Maps}

The relative position of each of the 65 items in terms of the first two factors can be seen in Fig. 1. The vertical axis represents Factor 1 (impact on species); the horizontal axis represents Factor 2 (human benefits). Items at the extreme bottom of Factor 1 are judged as having little adverse impact on species, whereas items near the top are perceived as having a high impact. On the horizontal dimension, items at the far right are construed as offering great human benefits, whereas items at the far left are seen to offer little or no human benefits.

Insert Fig. 1 about here

Items appearing in the upper right quadrant are those that have a high impact on species, but are perceived as highly beneficial to humans. Development of housing is the most extreme item in this quadrant, reflecting the difficult ecological tradeoffs inherent in satisfying this human requirement. Also in this quadrant are dams, mass farming practices, and urbanization. Items in the lower right quadrant are also perceived as beneficial, but are seen as having little effect on natural environments. Items in this quadrant include outdoor recreation, travel and tourism, urban water usage, and automobiles. The lower left quadrant consists of those items perceived to provide little human benefits, and to have little impact on nature. By far, the most extreme item in this quadrant are cigarettes, seen as having few benefits and virtually no impact on nature. Also in this quadrant are four of the five natural hazards. Finally, items found in the upper left quadrant seem to represent the practices that are most associated with ecological risk. These include the loss of animal and plant species, the loss of wetlands and habitats in general. Other items perceived as having a high impact on nature and low human benefits include nuclear war, poaching, and the belief that humans have dominion over nature. 
The relative position of each item in terms of Factor 1 (impact on species) and Factor 3 (impact on humans) can be seen in Fig. 2. On this map, the vertical axis represents Factor 1 and the horizontal axis represents Factor 3. Items in the upper right quadrant are those which are construed as posing high impacts on nonhuman species and high impact on humans. This quadrant consists of the most notable environmental threats including climate change, ozone depletion, population growth, and nuclear war. The right lower quadrant displays items that have minimal impact on species, but are seen as having high impact on humans, including cigarettes, television, and air pollution. In the upper left quadrant are the items that greatly affect species while at the same time have limited impact on humans, including the loss of animal and plant species, the loss of wetlands, poaching, and hunting. Finally, in the lower left quadrant are the items that have minimum impact on both species and humans, including collecting wilderness souvenirs, golf courses, scuba diving, and fireplaces.

Insert Fig. 2 about here

\subsection{Relationships Between Factors and Perceived Risk to Nature}

Next, we consider how these factors are correlated with the respondents' perceptions of the overall riskiness of items for natural environments. Although it will eventually be important to investigate the relation of this factor structure and expert assessment of ecological risks associated with each item, currently we only have data regarding the relation between the factors and our respondents' ratings of general ecological risk. Impact on species (Factor 1) not only accounted for the greatest amount of variance in the factor model, it also had the strongest 
Characterizing Perception of Ecological Risk

correlation with general riskiness $(r=.58 ; p<.01)$. In addition, perceived human benefits $(r=-$ $.51 ; p<.01)$, and impact on humans $(r=.48 ; p<.01)$ were strongly correlated with general ecological risk.

In contrast with other risk perception studies focused on technological hazards and human health, no correlation was found between perceived avoidability/controllability and perceived general ecological risk. This result suggests that avoidability may be seen as more associated with those activities involved in risk management (e.g., current levels of regulation, time and money spent preparing for, and responding to, consequences of the events) than in the absolute

judgment of risk. Another interpretation is that environmental risks may be viewed as markedly less amenable to risk management efforts than are human health risks. This difference may be attributable to the extent to which ecological risks are, at a global scale, the result of billions of individual decisions.

\subsection{Selected Comparisons}

We turn from the overall factor structure to briefly consider two of many possible comparisons among selected items. These comparisons indicate the kinds of insights to be drawn from detailed examination of responses among items. One comparison involves two items concerned with management of sewage. The respondents clearly perceived the disposal of untreated sewage in oceans as posing more overall risk $(M=2.25)$ than the disposal of treated sewage in oceans or lakes $(M=1.11)$. A review of the factor scores for these items reveals substantial differences on three of the five factors. Untreated sewage was perceived as having a higher impact on species (Factor 1) than treated sewage (.41 as compared to -.31), offering fewer human benefits (Factor 2; -.95 as compared to .23), and being more avoidable (Factor 4; 1.09 as compared to .50). Regardless of whether there is an actual difference in ecological risk stemming from these 
practices (some scientific research suggests that marine disposal of untreated sewage may be benign in certain locations), ${ }^{(17.18)}$ there clearly is a perceptual difference in terms of impacts on species, human benefits, and avoidability. These sorts of findings may help risk managers understand the public response to controversial ecological practices, and help them develop effective ways of communicating with the public regarding these issues.

A second set of comparisons examines indirect and direct sources of risk, and the consequences of those risks for ozone-related items (including air conditioning, aerosol cans, CFC emissions, and ozone depletion). In terms of overall riskiness, ozone depletion was considered the most risky $(M=2.51)$ closely followed by CFC emissions $(M=2.22)$, its direct cause. Two major sources of CFC emissions, air conditioning $(M=.75)$ and aerosol cans $(M=$ 1.43) were each perceived as posing less overall risk than CFCs, which makes sense in light of the fact that each source is only part of the CFC problem. Ozone depletion was perceived as having a much higher impact on species (Factor 1), factor score of .34, than were its sources (i.e., CFC emissions, -.33 ; air conditioning, -.65 ; aerosol cans, -.77$)$. Air conditioning was perceived as offering significantly more human benefits (Factor 2), factor score of -.18 , than did the other three items (i.e., ozone depletion, -1.43 , CFC emissions, -1.61 , aerosol cans, -1.37 ). The large difference on this benefit factor between air conditioning and aerosol cans may explain the heightened perception of riskiness associated with aerosol cans as compared to air conditioning. Ozone depletion was perceived as having the highest impact on humans (Factor 3), factor score of 1.73, followed by CFC emissions (1.47), aerosol cans (.81), and air conditioning (.31). In terms of avoidability (Factor 4), aerosol cans were seen as the most avoidable (1.52), substantially more avoidable than air conditioning (.86) and CFC emissions (.84). Interestingly, the consequence (i.e., ozone depletion) was perceived as the least avoidable (.11) of the four items, presumably 
because causes are more directly controllable than consequences. Knowledge of impacts was low for all four items, ranging from -.94 for ozone depletion to -1.47 for air conditioning.

\section{DISCUSSION AND CONCLUSIONS}

While the limitations of the sample, in terms of size and representativeness, should be borne in mind, we believe these results provide a plausible conceptual framework for characterizing perceived ecological risk. The risk maps are simple, yet sensible. Given the complexity of ecological risk judgments, and the fact that the list of items and list of scales used in this study were so diverse, it is perhaps surprising that the five factor model identified here explains as much of the variance in the respondents' judgments as it does.

Admist the wealth of descriptive detail contained in the factor maps and other analyses presented here, there appear to be many notable and sometimes surprising findings. For example, the differential perceptions of consequences and their causes suggests the need for additional studies designed to characterize the mental models responsible for such differences. Also noteworthy is the finding that natural hazards rate relatively low on the hierarchy of perceived risks to nature despite the immense damage they are capable of causing. For example, the meteorite strike thought to have caused the extinction of the dinosaurs is also believed to have extinguished $50 \%$ of the species then in existence. Whereas risk from meteor strikes may be discounted because of their rarity, damaging floods and droughts are not so rare. In general, the relatively benign evaluation of natural forces in ecological risk perception parallels the benign view of nature as a contributor to human health risk (see, e.g., ref. no. 19). The strong inverse relation between human benefit (Factor 2) and perception of risk to nature also parallels results found with human health risk perceptions. Alhakami and Slovic ${ }^{(14)}$ have attributed the latter to 
an inability of people to clearly distinguish risk and benefit, perhaps due to reliance on affective (good/bad) evaluations as a primary cue from which both risk and benefit judgments are derived. However, we should caution against assuming these findings reflect the views of the general public until larger sample surveys are undertaken with more representative samples.

While these results are descriptively interesting, they are also likely to be prescriptively relevant for future ecological risk management efforts. One direct prescriptive use of these results may be to help understand current controversies about ecological risks (and helping to predict future ones) by clarifying the factors influencing public risk judgments. A second may be to help clarify key issues that should be emphasized in ecological risk communication efforts. A third use may be to determine the factors that should be highlighted in programs designed to change individual behavior in response to ecological risks, or to design societal incentives to foster cooperative efforts in commons dilemmas. A fourth use would be to provide a starting point for development of objective hierarchies that characterize the interests of various groups in public environmental decision contexts. ${ }^{(13)}$

Future research should build on these results in several ways, akin to the extensions of research on human health risk perception. One important step would be to expand the sample size and representativeness, and obtain judgments for several specific societal groups (e.g., environmentalists, journalists). A second step would be to obtain judgments from experts that could be compared to the lay judgments considered here. Still another focus might involve cross-cultural comparisons of perceived ecological risk, and examination of perceived risks in a specific hazard domain (e.g., risks to water or land resources). With further research, ecological risk perception may prove to be as rich, informative, and enduring a construct as its human health risk predecessor. 


\section{ACKNOWLEDGEMENT}

This research was supported by a Tri-Council Eco-Research grant from the Government of Canada to the University of British Columbia, and by an assistance agreement between the U.S. Environmental Protection Agency and Decision Research. McDaniels was supported by Westwater Research Centre at the University of British Columbia. We thank Mike Healey for providing an opportunity to conduct this research. We thank Bob Clemen, Jim Flynn, Robin Gregory, Steve Hrudey, Steve Johnson, Don MacGregor, C.K. Mertz, and Terre Satterfield for advice and encouragement. We thank Milena Calendino for able research assistance. Finally, we thank those who participated in the focus groups and the survey for their very considerable contributions, in the form of thoughts, feelings, and judgments about ecological risks.

Although the research described in this article has been funded in part by the U.S. Environmental Protection Agency under assistance agreement R-822464-01-0 to Decision Research, it has not been subjected to the Agency's peer and administrative review, and, therefore, may not necessarily reflect the views of the Agency and no official endorsement should be inferred. 


\section{REFERENCES}

1. P. Slovic, "Perception of Risk," Science 236, 280-285 (1987).

2. P. Slovic, "Perception of Risk: Reflections on the Psychometric Paradigm," in Social Theories of Risk, edited.by S. Krimsky and D. Golding (New York, Praeger, 1992), pp. 117-152.

3. National Research Council (NRC), Improving Risk Communication (Washington, DC, National Academy Press, 1989).

4. W.J. Burns, P. Slovic, R.E. Kasperson, J.X. Kasperson, O. Renn, and S. Emani, "Incorporating Structural Models Into Research on the Social Amplification of Risk: Implications for Theory Construction and Decision Making," Risk Analysis 13, 611-623 (1993).

5. R. Kasperson, O. Renn, P. Slovic, H. Brown, J. Emel, R. Goble, J. Kasperson, and S. Ratick, "The Social Amplification of Risk: A Conceptual Framework," Risk Analysis 8, 177-187 (1988).

6. R. Gregory, J. Flynn, and P. Slovic, "Technological Stigma," American Scientist (in press).

7. T. McDaniels, M. Kamlet, and G. Fischer, "Risk Perception and the Value of Safety," Risk Analysis 12, 495-503 (1992).

8. R. Lackey, "Ecological Risk Assessment," Symposium on Critical Issues in Risk Assessment (New Orleans, April, 1993).

9. G. Suter, Ecological Risk Assessment (Boca Raton, Louisiana, Lewis, 1993).

10. C. Travis and J. Morris, "The Emergence of Ecological Risk Assessment," Risk Analysis 12, 167-168 (1992).

11. B. Fischhoff, S. Lichtenstein, P. Slovic, S. Derby, and R. Keeney, Acceptable Risk (New York, Cambridge University Press, 1981).

12. S. Rayner and R. Cantor, "How Fair is Safe Enough? The Cultural Approach to Societal Technology Choice," Risk Analysis 7, 3-13 (1987). 
13. B. Fischhoff, S. Watson, and C. Hope, "Defining Risk," Policy Sciences 17, 123-139 (1984).

14. A. Alhakami and P. Slovic, "A Psychological Study of the Inverse Relationship Between Perceived Risk and Perceived Benefit," Risk Analysis 14(6), 1084-1096 (1994).

15. R. Gregory and R. Mendelsohn, "Perceived Risk, Dread, and Benefits," Risk Analysis 13, 259264 (1993).

16. D. MacGregor and P. Slovic, "Perception of Risk in Automotive Systems," Human Factors 31, $377-389$ (1989).

17. National Research Council (NRC), Managing Wastewater in Coastal Urban Areas (Washington, DC, National Academy Press, 1993).

18. Capital Regional District, Sewage Discharge: Effects on the Offshore Marine Environment. Liquid Waste Management Plan Information Paper No. 4 (Victoria, British Columbia, Author, 1992, September).

19. N. Kraus, T. Malmfors, and P. Slovic, "Intuitive Toxicology: Expert and Lay Judgments of Chemical Risks," Risk Analysis 12, 215-232 (1992). 


\section{ENDNOTES}

1. Two researchers took notes in each group. Each person then coded their notes as to potential items and scales. A graduate student compiled the content of each set of notes into a comprehensive list of items and scales using a simple union procedure. The researchers then reviewed the lists to eliminate redundancies. This process determined the lists of potential scales and items, which were edited slightly to insure clarity and make the judgment task feasible for individuals to complete at one administration.

2. We were surprised and moved by the extent of emotional reactions in the focus groups. In groups with individuals from diverse backgrounds, people were at times close to tears when reflecting on ecological risk. The profound sadness felt in response to threats to nature, and the frustration arising from an inability to reduce these threats was palpable. 
Table I. Description of Scales and Response Categories in Order Presented in the Survey

\begin{tabular}{|c|c|c|c|}
\hline & & \multicolumn{2}{|c|}{ Scale end points } \\
\hline \multicolumn{2}{|c|}{ Description of scale } & Low $(1)$ & High (7) \\
\hline Certainty & $\begin{array}{l}\text { Please rate how certain it is that the event has an impact on } \\
\text { natural environments }\end{array}$ & Not at all & Very \\
\hline Adaptability & $\begin{array}{l}\text { Please rate how well natural environments maintain their health } \\
\text { and productivity in response to the current level of each event }\end{array}$ & Cannot at all & Can fully \\
\hline Avoidability & $\begin{array}{l}\text { Please rate how avoidable the event is, in terms of how easy or } \\
\text { difficult it would be to avoid the occurrence of the event }\end{array}$ & Not at all & Completely \\
\hline Relevance to life & $\begin{array}{l}\text { Please rate how relevant the event is to your life, in terms of its } \\
\text { impact on natural environments }\end{array}$ & No & Direct \\
\hline Controllability & $\begin{array}{l}\text { Please rate how controllable is each event, in terms of people's } \\
\text { ability to control its impact on natural environments }\end{array}$ & Not at all & Very \\
\hline $\begin{array}{l}\text { Duration of } \\
\text { impacts }\end{array}$ & $\begin{array}{l}\text { Please rate the duration of the impacts that each event has } \\
\text { on natural environments }\end{array}$ & Short-term & Long-term \\
\hline Societal benefits & $\begin{array}{l}\text { Please rate how much you think the event may benefit the } \\
\text { functioning of your society }\end{array}$ & No & Great \\
\hline $\begin{array}{l}\text { Personal } \\
\text { benefits }\end{array}$ & $\begin{array}{l}\text { Please rate how much you think that you personally can } \\
\text { or do benefit from the event }\end{array}$ & No & Great \\
\hline $\begin{array}{l}\text { Scope of } \\
\text { impacts }\end{array}$ & $\begin{array}{l}\text { Please rate the scope of the impacts of the event, in terms } \\
\text { of the size of the area affected }\end{array}$ & Small & Widespread \\
\hline $\begin{array}{l}\text { Number of } \\
\text { people }\end{array}$ & $\begin{array}{l}\text { Please rate how many people are, or could be, affected by } \\
\text { the impact the event may have on natural environments }\end{array}$ & Very few & $\begin{array}{l}\text { A great } \\
\text { number }\end{array}$ \\
\hline Species loss & $\begin{array}{l}\text { Please rate the impacts of each event in terms of any potential } \\
\text { for loss of animal or plant species }\end{array}$ & No species & Many species \\
\hline Destructiveness & $\begin{array}{l}\text { Please rate how destructive the event is or can be, in terms of its } \\
\text { impacts on affected natural environments }\end{array}$ & $\begin{array}{l}\text { No adverse } \\
\text { impacts }\end{array}$ & $\begin{array}{l}\text { Complete } \\
\text { destruction }\end{array}$ \\
\hline Emotionality & $\begin{array}{l}\text { Please rate how much negative emotion (i.e., anger, fear, } \\
\text { disgust) you feel when you think about the event and its } \\
\text { impacts on natural environments }\end{array}$ & No & High \\
\hline $\begin{array}{l}\text { Equitableness of } \\
\text { outcomes }\end{array}$ & $\begin{array}{l}\text { Please rate the equity of each event in terms of whether } \\
\text { those who receive the benefits are the same people who incur } \\
\text { the costs }\end{array}$ & Inequitable & Equitable \\
\hline $\begin{array}{l}\text { Ethicality of } \\
\text { event }\end{array}$ & $\begin{array}{l}\text { Please rate how ethical you perceive each event to be, in } \\
\text { terms of its impact on natural environments }\end{array}$ & $\begin{array}{l}\text { Very } \\
\text { unethical }\end{array}$ & $\begin{array}{l}\text { Completely } \\
\text { ethical }\end{array}$ \\
\hline $\begin{array}{l}\text { Immediacy of } \\
\text { effects }\end{array}$ & $\begin{array}{l}\text { Please rate the immediacy of each event, in terms of how } \\
\text { soon its effects on natural environments may be experienced }\end{array}$ & Immediate & $\begin{array}{l}\text { Far in the } \\
\text { future }\end{array}$ \\
\hline $\begin{array}{l}\text { Infringement on } \\
\text { rights }\end{array}$ & $\begin{array}{l}\text { Please rate to what extent the event infringes on the rights } \\
\text { of nonhuman species }\end{array}$ & Does not & Greatly \\
\hline
\end{tabular}


(Table I cont.)

\begin{tabular}{|c|c|c|c|}
\hline & & \multicolumn{2}{|c|}{ Scale end points } \\
\hline \multicolumn{2}{|c|}{ Description of scale } & Low (1) & $\operatorname{High}(7)$ \\
\hline $\begin{array}{l}\text { Reversibility of } \\
\text { impacts }\end{array}$ & $\begin{array}{l}\text { Please rate the extent to which the impacts on natural } \\
\text { environments associated with the event are reversible (i.e., the } \\
\text { ability of natural environments to return to pre-event } \\
\text { conditions) }\end{array}$ & Irreversible & Reversible \\
\hline $\begin{array}{l}\text { Human } \\
\text { suffering }\end{array}$ & $\begin{array}{l}\text { Please rate how much human suffering could result from } \\
\text { the event as a result of its impact on natural environments }\end{array}$ & No & Great \\
\hline $\begin{array}{l}\text { Animal/plant } \\
\text { suffering }\end{array}$ & $\begin{array}{l}\text { Please rate how much suffering by animals or plants could } \\
\text { occur as a result of the event }\end{array}$ & No & Great \\
\hline $\begin{array}{l}\text { Understand- } \\
\text { ability }\end{array}$ & $\begin{array}{l}\text { Please rate how easy or difficult it is to understand the } \\
\text { impacts each event has on natural environments }\end{array}$ & Simple to & Hard to \\
\hline Predictability & $\begin{array}{l}\text { Please rate how well impacts on natural environments } \\
\text { associated with the event can be predicted }\end{array}$ & Not at all & Very \\
\hline $\begin{array}{l}\text { Recognition of } \\
\text { impacts }\end{array}$ & $\begin{array}{l}\text { Please rate how recently potential impacts on natural } \\
\text { environments associated with each event have been recognized } \\
\text { by experts }\end{array}$ & Recently & $\begin{array}{l}\text { For a long } \\
\text { time }\end{array}$ \\
\hline $\begin{array}{l}\text { Observability of } \\
\text { impacts }\end{array}$ & $\begin{array}{l}\text { Please rate how observable are the impacts on natural } \\
\text { environments associated with the event }\end{array}$ & Not at all & Very \\
\hline Media attention & $\begin{array}{l}\text { Please rate how much attention the media has given to the } \\
\text { event, in terms of its impact on natural environments }\end{array}$ & No & A great deal \\
\hline $\begin{array}{l}\text { Regulatability of } \\
\text { risk }\end{array}$ & $\begin{array}{l}\text { Please rate the extent to which the event can be regulated } \\
\text { by governments }\end{array}$ & Cannot be & $\begin{array}{l}\text { Can be } \\
\text { completely }\end{array}$ \\
\hline $\begin{array}{l}\text { Availability of } \\
\text { alternatives }\end{array}$ & $\begin{array}{l}\text { Please rate the extent to which there are reasonable } \\
\text { alternatives to the event, or to the practices that lead to the } \\
\text { event }\end{array}$ & Not available & Are available \\
\hline Goodness & $\begin{array}{l}\text { Please rate whether you think, in general, the event is good or } \\
\text { bad }\end{array}$ & Very bad & Very good \\
\hline $\begin{array}{l}\text { Human health } \\
\text { risk }\end{array}$ & $\begin{array}{l}\text { Please rate the extent to which the event and its impact on } \\
\text { natural environments pose a risk to human health }\end{array}$ & No risk & A great risk \\
\hline $\begin{array}{l}\text { General accept- } \\
\text { ability of event }\end{array}$ & $\begin{array}{l}\text { Please rate the acceptability of each event, in terms of its } \\
\text { general impact on human life and natural environments }\end{array}$ & Not at all & Completely \\
\hline $\begin{array}{l}\text { General } \\
\text { riskiness }\end{array}$ & $\begin{array}{l}\text { Please rate how "risky in general" you think each event is } \\
\text { in terms of its impacts on the health and productivity of natural } \\
\text { environments }\end{array}$ & Poses no risk & $\begin{array}{l}\text { Poses great } \\
\text { risk }\end{array}$ \\
\hline
\end{tabular}


Table II. Means and Standard Deviations of Judgment Scale Ratings

\begin{tabular}{|c|c|c|c|}
\hline Characteristic & Scale end points & Mean & $\begin{array}{l}\text { Standard } \\
\text { deviation }\end{array}$ \\
\hline Certainty & Not at all $\rightarrow$ very & 1.54 & .83 \\
\hline Animal/plant suffering & No - great & 1.31 & .97 \\
\hline Infringement on rights & Does not - greatly & 1.31 & 1.04 \\
\hline Duration of impacts & Short-term $\rightarrow$ long-term & 1.25 & .99 \\
\hline General acceptability of risk & Poses no risk $\rightarrow$ poses great risk & 1.13 & 1.00 \\
\hline Number of people & Very few $\rightarrow$ a great number & 1.02 & 1.01 \\
\hline Availability of alternatives & Not available $\rightarrow$ are available & 1.00 & 1.13 \\
\hline Destructiveness & No adverse impacts $\rightarrow$ complete destruction & .90 & .99 \\
\hline Predictability & Not at all - very & .81 & .58 \\
\hline Scope of impacts & Small $\rightarrow$ widespread & .73 & 1.19 \\
\hline Species loss & No species $\rightarrow$ many species & .73 & 1.05 \\
\hline Human health risk & No risk $\rightarrow$ a great risk & .68 & 1.09 \\
\hline Relevance to life & No $\rightarrow$ direct & .68 & .89 \\
\hline Controllability & Not at all $\rightarrow$ very & .64 & 1.07 \\
\hline Observability of impacts & Not at all $\rightarrow$ very & .64 & .85 \\
\hline Regulatability of risk & Cannot be $\rightarrow$ can be completely & .64 & 1.30 \\
\hline Emotionality & No $\rightarrow$ high & .60 & 1.23 \\
\hline Human suffering & No $\rightarrow$ great & .59 & 1.05 \\
\hline Recognition of impacts & Recently $\rightarrow$ for a long time & .39 & .69 \\
\hline Avoidability & Not at all $\rightarrow$ completely & .27 & 1.19 \\
\hline Media attention & No $\rightarrow$ a great deal & .18 & 1.12 \\
\hline Reversibility of impacts & Irreversible $\rightarrow$ reversible & -.21 & .83 \\
\hline Immediacy of effects & Immediate $\rightarrow$ far in the future & -.71 & .69 \\
\hline Adaptability & Cannot at all $\rightarrow$ can fully & -.72 & .89 \\
\hline Equitableness of outcomes & Inequitable - equitable & -.76 & .61 \\
\hline Ethicality of event & Very unethical $\rightarrow$ completely ethical & -.83 & 1.05 \\
\hline General acceptability of event & Not at all $\rightarrow$ completely & -.92 & 1.10 \\
\hline Societal benefits & No $\rightarrow$ great & -1.00 & 1.31 \\
\hline Understandability & Simple to $\rightarrow$ hard to & -1.14 & .73 \\
\hline Personal benefits & No - great & -1.29 & 1.32 \\
\hline Goodness & Very bad - very good & -1.33 & 1.05 \\
\hline
\end{tabular}


Table III. Ratings of 65 Items on Overall Risk to Natural Environments

\begin{tabular}{ll}
\hline Item & Mean \\
\hline Nuclear war & 2.69 \\
Loss of animal species & 2.53 \\
Depletion of ozone layer & 2.51 \\
Loss of habitats for animals/fish & 2.51 \\
Loss of plant species & 2.51 \\
Deforestation (permanent removal of forest cover) & 2.43 \\
Loss of wetlands & 2.42 \\
Air pollution & 2.26 \\
Disposal of untreated sewage in oceans & 2.25 \\
Emission of ozone depleting gases (CFCs) & 2.22 \\
Clearcutting forests & 2.11 \\
Climate change (e.g., global warming) & 2.06 \\
Acid rain & 1.99 \\
Conventional warfare & 1.99 \\
Production and disposal of toxic chemicals & 1.96 \\
Belief that humans have dominion over nature & 1.77 \\
Waste production in modern society & 1.68 \\
Consumption levels in modern society & 1.63 \\
Population growth & 1.61 \\
Lack of regard for nonhuman rights & 1.60 \\
Nuclear power plants & 1.57 \\
Intensive commercial fishing & 1.50 \\
Value system oriented toward material wealth & 1.44 \\
Aerosol cans & 1.43 \\
Driftnet fishing & 1.39 \\
Energy production from nonrenewable resources & 1.38 \\
Drought & 1.33 \\
Driving automobiles & 1.28 \\
Earthquakes & 1.07 \\
Urbanization (continued growth of large cities) & 1.28 \\
Poaching (illegal harvest of wild animals) & 1.28 \\
Transporting of oil & 1.15 \\
Cigarette smoking & \\
Disposal of treated sewage in oceans or lakes & \\
Burning of waste materials (incineration) & \\
Society's desire for continued economic growth & \\
& \\
\hline
\end{tabular}

(Table III continued) 
(Table III cont.)

\begin{tabular}{lc}
\hline Item & Mean \\
\hline Soil erosion & 1.06 \\
Floods & 1.04 \\
Large scale/multinational business & 1.04 \\
& \\
Disposal of municipal waste in landfills & 1.03 \\
Increasing reliance on technology & .99 \\
Biotechnology (genetically altering plants and animals) & .99 \\
Development of land for housing & .92 \\
Pesticides & .90 \\
Meteors colliding with Earth & .89 \\
Dams on rivers & .86 \\
Hunting of animals & .85 \\
Volcanos & .82 \\
Mass production farming practices & .82 \\
Disconnection of modern life from natural environments & .76 \\
Beef production & .75 \\
Air conditioning & .75 \\
Mining & .74 \\
Capitalism & .61 \\
Fertilizers & .53 \\
Urban water usage & .50 \\
Irrigated agriculture & .47 \\
Transplanting of animal and plant species & .32 \\
Collecting wilderness souvenirs.(e.g., plants, seashells) & -.53 \\
Television & -.56 \\
Golf courses & -.72 \\
Tourism and travel & -1.42 \\
Fireplaces & -1.78 \\
Scuba diving & -1.85 \\
Outdoor recreation (e.g., skiing, hiking, climbing) & \\
\hline & \\
\hline
\end{tabular}

Note. Scale ranged from -3 (poses no risk) to +3 (poses great risk). 


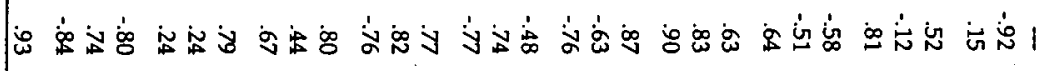

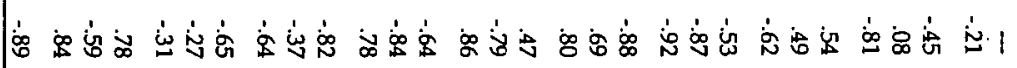

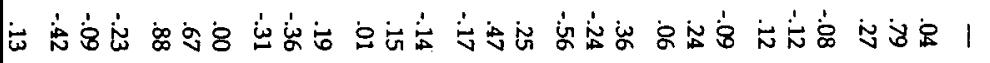

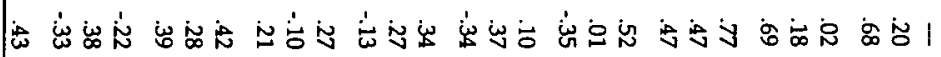

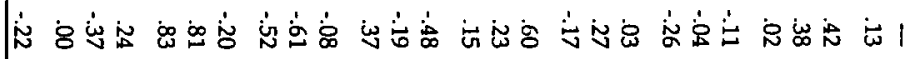

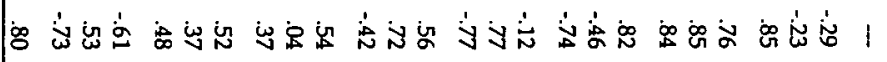

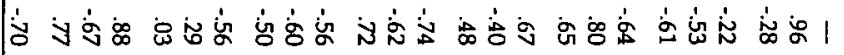

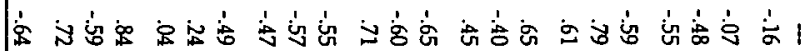

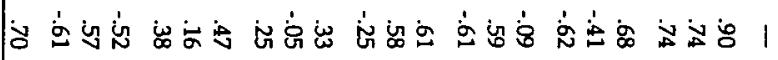

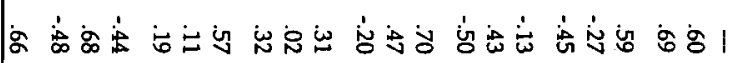

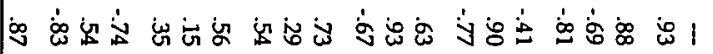

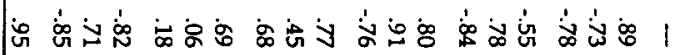

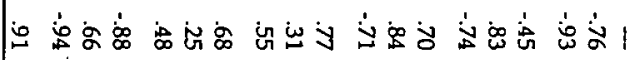

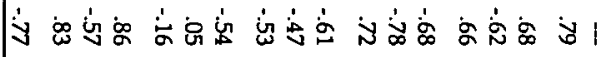

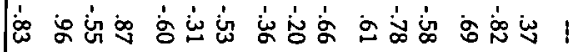

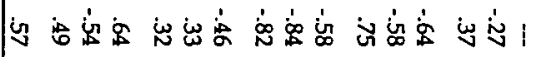

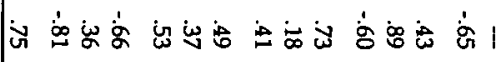

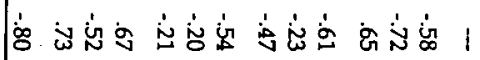

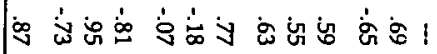

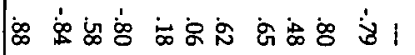

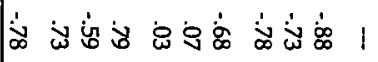

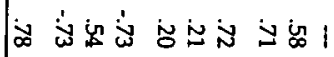

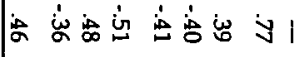

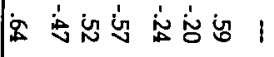

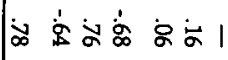

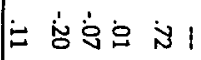

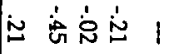

这安?

ळ i 1

Certainty

Adaptability Avoidability Relevance to life Controllability

Duration of impacts Societal benefits

Personal benefits

Scope of impacts

Number of people

Species loss

Destructiveness

Emotionality

Equitableness of outcomes

Ethicality of event

Immediacy of effects

Infringement on rights

Reversibility of impacts

Human suffering

Animal/plant suffering

Understandability

Predictability

Recognition of impacts

Observability of impacts

Media attention

Regulatability of risk

Availability of alternatives

Goodness

Human heal th risk

Generally acceptable event

General riskiness 
Table V. Rotated Factor Loadings for 30 Risk Characteristic Scales

\begin{tabular}{|c|c|c|c|c|c|}
\hline Characteristic & Factor 1 & Factor 2 & Factor 3 & Factor 4 & Factor 5 \\
\hline Species loss & .84 & & & & \\
\hline Infringement on rights & .80 & & & & \\
\hline Animal/plant suffering & .77 & & & & \\
\hline Destructiveness & .73 & & .45 & & \\
\hline Adaptability & -.72 & & & & -.43 \\
\hline Reversibility of impacts & -.72 & & & & \\
\hline Duration of impacts & .71 & & .59 & & \\
\hline Emotionality & .63 & -.47 & & & \\
\hline Ethicality of event & -.62 & .58 & & & \\
\hline Certainty & .54 & & .49 & & .50 \\
\hline Societal benefits & & .88 & & & \\
\hline Personal benefits & & .88 & & & \\
\hline Goodness & & .76 & & & \\
\hline Equitableness of outcomes & -.46 & .73 & & & \\
\hline General acceptability of event & -.58 & .65 & & & \\
\hline Human suffering & & -.60 & .59 & & \\
\hline Number of people & & & .91 & & \\
\hline Relevance to life & & & .80 & & \\
\hline Scope of impacts & .56 & & .74 & & \\
\hline Human health risk & & -.59 & .65 & & \\
\hline Controllability & & & & .92 & \\
\hline Avoidability & & & & .89 & \\
\hline Availability of alternatives & & & & .88 & \\
\hline Regulatability of risk & & & & .86 & \\
\hline Observability of impacts & & & & & .74 \\
\hline Predictability & .48 & & & & .73 \\
\hline Recognition of impacts & & & & -.45 & .69 \\
\hline Understandability & -.47 & .45 & & & -.69 \\
\hline Immediacy of effects & & .48 & & .41 & -.59 \\
\hline Media attention & & & .56 & & .58 \\
\hline
\end{tabular}

Note. Loadings with absolute values below 40 are omitted from the table. Names for the factors are discussed in the text. 
Table VI. Ten Highest and Ten Lowest Items for the Five Factors That Characterize Perceived Ecological Risk

\begin{tabular}{|c|c|c|c|c|c|c|c|c|c|}
\hline \multicolumn{2}{|c|}{$\begin{array}{c}\text { Factor } 1 \\
\text { Impact on species }\end{array}$} & \multicolumn{2}{|c|}{$\begin{array}{c}\text { Factor } 2 \\
\text { Human benefits } \\
\end{array}$} & \multicolumn{2}{|c|}{$\begin{array}{c}\text { Factor } 3 \\
\text { Impact on humans } \\
\end{array}$} & \multicolumn{2}{|l|}{$\begin{array}{c}\text { Factor } 4 \\
\text { Avoidability } \\
\end{array}$} & \multicolumn{2}{|c|}{$\begin{array}{c}\text { Factor } 5 \\
\text { Knowledge of impacts } \\
\end{array}$} \\
\hline Cigarettes & -3.43 & Cigarettes & -2.38 & Collect souvenirs & -2.45 & Meteors & -3.45 & Television & -1.84 \\
\hline Scuba diving. & -1.78 & CFC emissions & -1.60 & Scuba diving & -2.29 & Volcanos & -2.92 & Biotechnology & -1.74 \\
\hline Fireplaces & -1.77 & Conventional war & -1.52 & Golf courses & -2.28 & Earthquakes & -2.58 & Meteors & -1.72 \\
\hline Earthquakes & -1.74 & Ozone depletion & -1.43 & Poaching & -1.97 & Floods & -2.57 & Scuba diving & -1.50 \\
\hline Television & -1.67 & Aerosol cans & -1.37 & Hunting & -1.95 & Drought & -2.44 & Air conditioning & -1.47 \\
\hline Recreation & -1.57 & Nuclear war & -1.32 & Fireplaces & -1.66 & Economic growth & -.99 & Fireplaces & -1.34 \\
\hline Floods & -1.29 & Acid rain & -1.13 & Volcanos & -1.36 & Climate change & -.93 & Big business & -1.23 \\
\hline Drought & -.95 & Earthquakes & -1.10 & Driftnet fishing & -1.04 & Population & -.84 & Climate change & -1.20 \\
\hline Burning of waste & -.87 & Floods & -1.08 & Dams & -1.03 & Capitalism & -.78 & Monetary values & -1.20 \\
\hline Travel & -.86 & Poaching & -1.03 & Meteors & -.89 & Technology & -.64 & Disconnection & -1.18 \\
\hline Climate change & .84 & Technology & 1.06 & Waste production & 1.02 & Hunting & .85 & Hunting & 1.08 \\
\hline Deforestation & 1.00 & Dams & 1.19 & Monetary values & 1.14 & Air conditioning & .86 & Loss of habitat & 1.19 \\
\hline Poaching & 1.03 & Mass farming & 1.22 & Urbanization & 1.14 & Poaching & .87 & Floods & 1.39 \\
\hline Nuclear war & 1.26 & Irrigation & 1.29 & Technology & 1.32 & Deforestation & .92 & Air pollution & 1.40 \\
\hline Disregard rights & 1.30 & Urbanization & 1.44 & Population growth & 1.36 & Driftnet fishing & 1.05 & Housing & 1.49 \\
\hline Belief in dominion & 1.56 & Urban water use & 1.78 & Climate change & 1.37 & Untreated sewage & 1.09 & Drought & 1.51 \\
\hline Loss of habitat & 1.60 & Automobiles & 1.83 & CFC emissions & 1.47 & Clearcutting & 1.09 & Automobiles & 1.53 \\
\hline Animal loss & 2.01 & Travel & 2.13 & Air pollution & 1.55 & Golf courses & 1.26 & Deforestation & 1.78 \\
\hline Plant loss & 2.03 & Housing & 2.29 & Ozone depletion & 1.73 & Aerosol cans & 1.52 & Clearcutting & 1.90 \\
\hline Wetland loss & 2.06 & Recreation & 2.55 & Automobiles & 1.75 & Cigarettes & 1.55 & Earthquakes & 1.90 \\
\hline
\end{tabular}

Note. The table entries are factor scores calculated using regression procedures, as described in the text. 


\section{FIGURE CAPTIONS}

Fig. 1. Map of Factor 1 vs Factor 2.

Fig. 2. Map of Factor 1 vs Factor 3. 


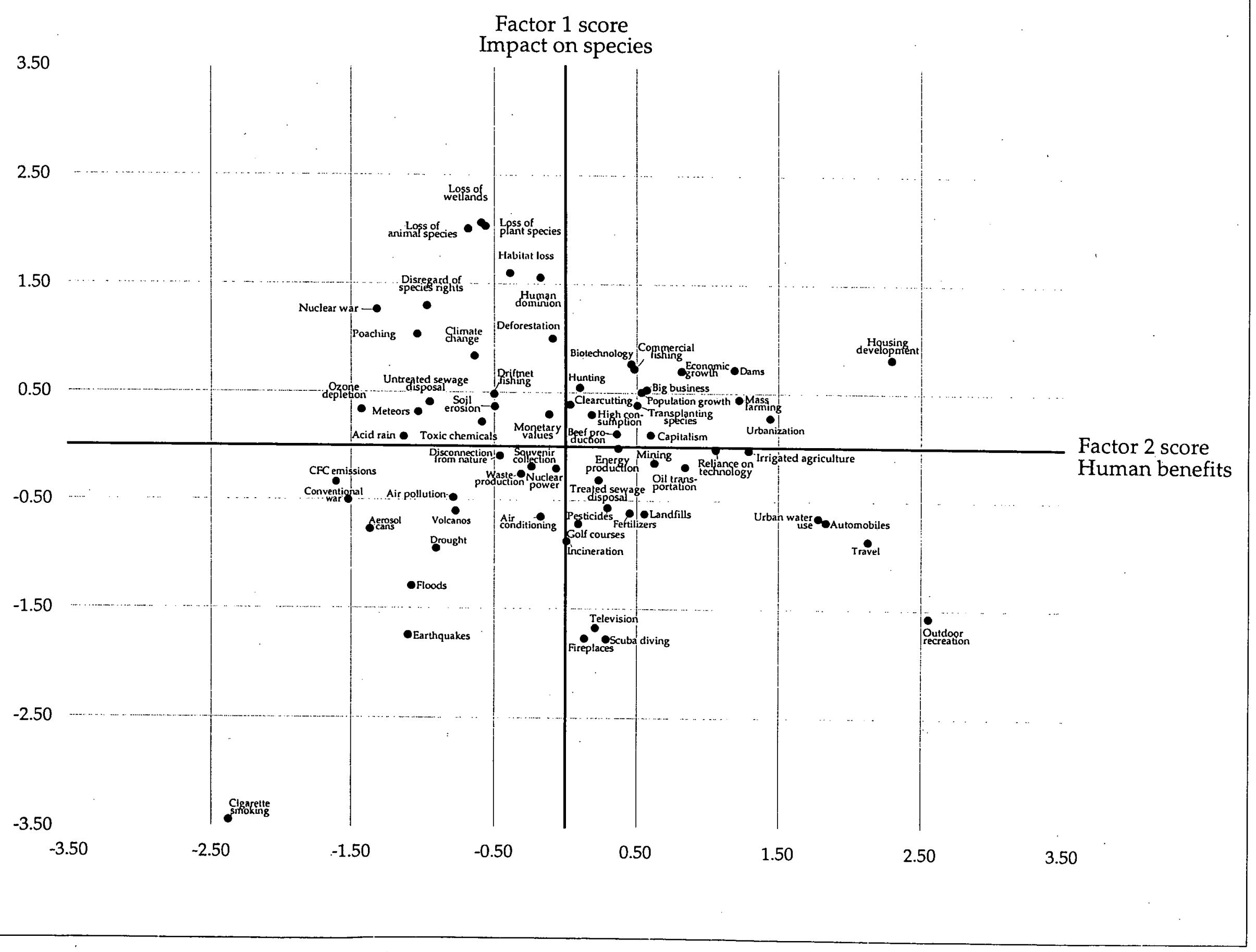


Factor 1 score

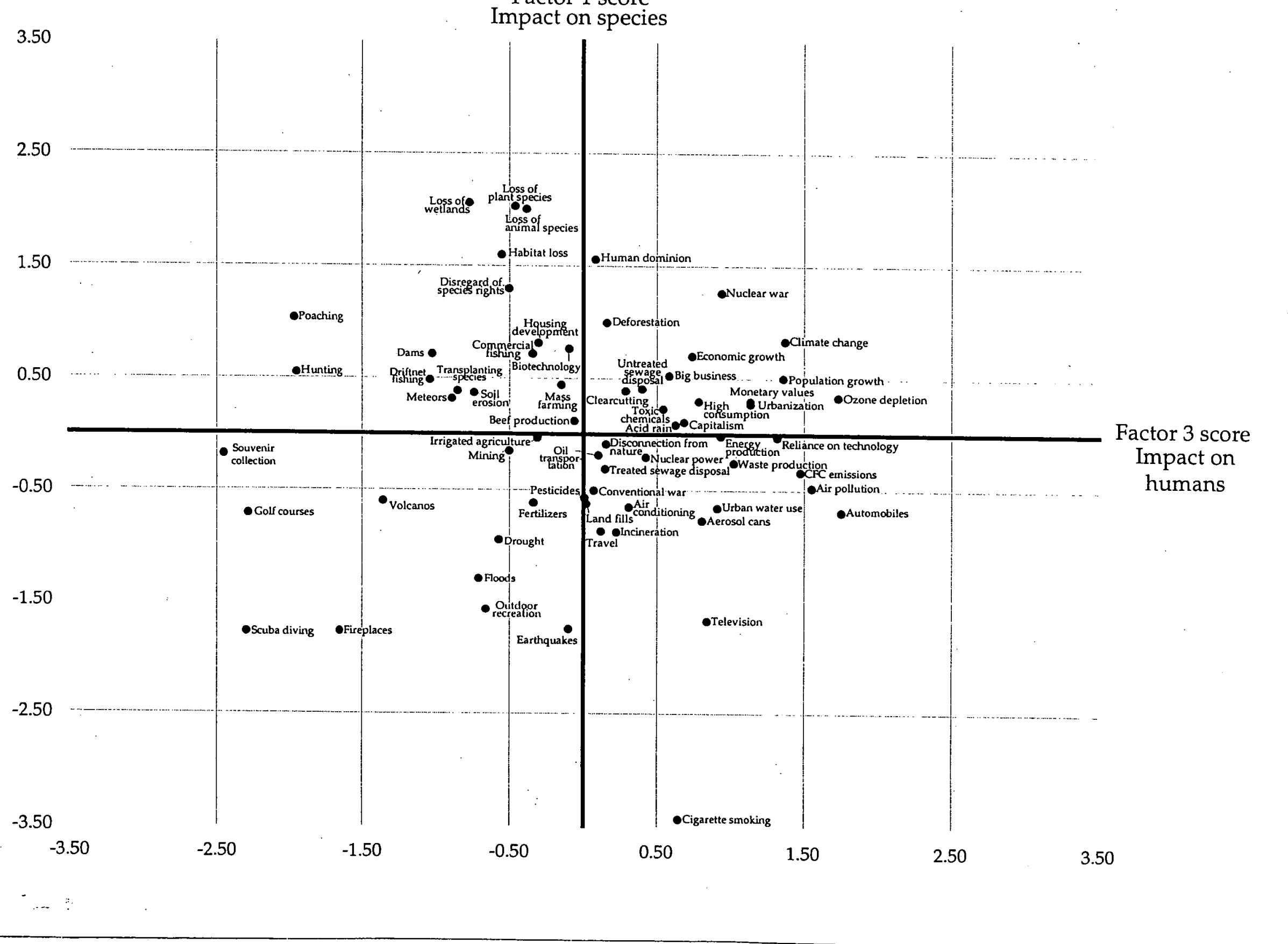

